\title{
Bringing the World to the Classroom: Teaching Statistics and Programming in a Project-Based Setting
}

Cosima Meyer, University of Mannheim, Germany

ABSTRACT This article introduces how to teach an interactive, one-semester-long statistics and programming class. The setting also can be applied to shorter and longer classes as well as introductory and advanced courses. I propose a project-based seminar that also encompasses elements of an inverted classroom. As a result of this combination, the seminar supports students' learning progress and also creates engaging virtual classes. To demonstrate how to apply a project-based seminar setting to teaching statistics and programming classes, I use an introductory class to data wrangling and management with the statistical software program R. Students are guided through a typical data science workflow that requires data management and data wrangling and concludes with visualizing and presenting first research results during a simulated mini-conference.

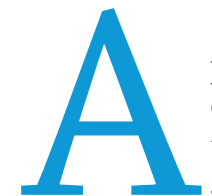

confident application of methods is necessary to perform high-quality research both within and outside of academia. Whereas much of the statistical and methodological training that political science students experience is in high demand, we can provide better integration of methods courses in the curriculum (Adeney and Carey 2009; Williams et al. 2021) and also make statistics and programming classes more accessible for students (Asal et al. 2018; Forte 1995). This article describes an approach to stimulate engaging and problem-based learning environments using an inverted classroom setting applicable for both in-class and virtual seminar settings. Although the article uses a working example from political science and the programming language $R$, the setup also can be transferred to other disciplines and other programming languages.

Different statistical languages typically are taught at both undergraduate and graduate levels in programming and statistics courses in political science. They often include SPSS, Stata, R, and Python. Because R and Python are the only fully opensource languages among these four languages that also are highly versatile, I am convinced that they have substantial advantages

Cosima Meyer (iD is a PhD candidate and former lecturer at the University of Mannheim / Graduate School of Economic and Social Sciences. She now works as a data scientist. She can be reached at cosima.meyer@gmail.com. over SPSS and Stata. In addition to the versatility in using R and Python for various tasks beyond statistical analysis (Ozgur et al. 2017), they are among the top languages requested in nonacademic professions (daSilva 2019).

Because learning a programming language requires constant practice, I approached this challenge from two different angles: (1) interactive project-based group work with integrated peer support, and (2) elements of an inverted classroom. The inverted classroom allowed me to provide input but left enough space for students to (re)apply learned skills and to practice them with online learning platforms. This was further supported by interactive group work that required students to work continuously on their research projects. Using a combination of RStudio Cloud, GitHub, and R Markdown, I was able to introduce students to a coherent workflow that generates reproducible research. Teaching transferrable skills as part of the curriculum is essential because it better prepares students for the future job market. The proposed course setting offers various transferable skills, ranging from specific programming skills to critical and analytical thinking, to teamwork and presentation experiences.

This article proposes an easily applicable step-by-step guide for turning a statistics course into an interactive seminar setting that allows students to experience access to real data and to practice their skills early in the program. 
COURSE SETUP: USING PROJECT-BASED LEARNING AND AN INVERTED CLASSROOM SETTING

I taught the seminar in both in-class and virtual settings with undergraduate political science students. To facilitate communication, I relied on an interactive communication platform (e.g., Slack) that increases peer support and cohesion. Although the class sizes were relatively small (i.e., fewer than 20 students), the performed, for example, based on their interests and mixed levels of previous skills. ${ }^{1}$ For the example seminar, I asked students to submit a research question at the beginning of the semester. Students then were grouped based on an overarching thematical overlap. The key task during the group work was to merge different datasets, wrangle the data, and generate first plots to visualize the initial findings. Thus, the common denominator for

\section{The project-oriented work setting of the seminar mimics both academic and nonacademic workflows, thereby preparing students for future jobs in different disciplines.}

group-work component that integrates peer support also should accommodate larger class sizes.

To create an inclusive learning environment that equips and empowers students with methodological skills, I did not request any prerequisites. Therefore, the courses were heterogeneous, including students who had prior statistical knowledge through their undergraduate courses and those who were not previously exposed to statistical programming languages or statistics.

I am convinced that interactive learning generates the greatest learning success-and even more so in a methods course. Therefore, I used an inverted classroom setting with a project-based learning approach. Proponents of both approaches often highlight that they encourage student participation (Krajcik and Blumenfeld 2006; Låg and Sæle 2019). Project-based learning is a teaching and learning approach that successfully contributes to students' learning progress. According to Krajcik and Blumenfeld (2006, 317), "[p]roject-based learning allows students to learn by doing and applying ideas. Students engage in real-world activities." Using this approach, students practice their statistical knowledge from the first class session and apply it early to their projects. It also combines recommendations by Bailey (2019) to apply the knowledge to something meaningful and by Knoll (2016) to learn by using project-based learning approaches. I divided students into small research groups that collaborated throughout the course and used synergetic effects to learn from and with one another. The project-oriented work setting of the seminar mimics both academic and nonacademic workflows, thereby preparing students for future jobs in different disciplines.

An inverted classroom, also called a flipped classroom, describes a setting in which "activities traditionally done by students outside class (e.g., practicing problem-solving) are moved into the classroom session, whereas what is traditionally done in class (e.g., expository, information transmission teaching) is done outside and prior to class" (Låg and Sæle 2019, 1). As Låg and Sæle $(2019,2)$ summarized, an inverted classroom can allow students to learn at their own pace in a more personalized teaching and learning environment. It also encourages students to learn independently and to become more responsible for their learning success. I am convinced that an inverted classroom is favorable for methods courses because learning a new programming language is a highly independent endeavor that often requires much self-effort to find a workable solution (Chen et al. 2020; Shaw 2012).

\section{Define Project Groups at the Beginning}

Grouping students into project groups at the beginning of the course is essential. Depending on the class size, ideal working groups usually consist of two to three students. Grouping can be grouping students was driven primarily by an overlap in potential datasets. Because the example seminar was an undergraduate class that introduces students to $\mathrm{R}$ and statistics, additional guidance was required. Another option is grouping students randomly; instructors then may distribute problem descriptions that students must solve during the semester. ${ }^{2}$

\section{Mimic a Typical Workflow}

To demonstrate a typical academic workflow, I followed single steps to replicate the figures of one important article in the field of conflict studies, ${ }^{3}$ dividing the seminar into five thematic blocks: (1) introduction, (2) data wrangling and merging, (3) data visualization, (4) a hackathon, and (5) a mini-conference. Table 1 illustrates an exemplary schedule for the course, which may be adjusted to different topics. The course also has been taught as a block seminar using a similar plan.

To reduce the heterogeneity in knowledge as best as possible, I first assigned a short introductory course in $\mathrm{R}$, which students were required to complete before the first class session. Every student thus had at least some previous experience using $R$. Experiencing $\mathrm{R}$ for the first time at their own pace allowed students to take the time they needed without feeling limited or peer pressure in the classroom.

The scientific study for replication can be exchanged easily because the process to replicate the study likely follows similar steps. To provide a coherent in-class working example that allows students to follow easily, I replicated a scientific paper. Because students were required to submit a short research paper with a visualization of their results, I used the in-class examples to demonstrate how this can be done. The in-class sessions were divided between input from my side (i.e., show and tell) and group work to (re)apply previously learned skills (i.e., hands-on). During the showand-tell section, I used the working example to demonstrate the different steps in a data science workflow (e.g., accessing the data, wrangling the data, and presenting the data). To enable students to follow the single steps, I also implemented short practical sections to directly apply the new skills. For instance, when I explained how to generate a new variable, I first demonstrated using the working example. I then included a short practical session, in which students were asked to apply the same approach to generate other new variables required for processing the working example. During the hands-on sections, which were always part of the seminar sessions, students worked in their group with their own datasets on the steps discussed during the show-and-tell section. ${ }^{4}$ This way, the instructor can continuously supervise the process and provide guidance when necessary. Based on my experience, it also generates a collaborative atmosphere among the students and the instructor. 
Table 1

Schedule for the Course (Example)

\begin{tabular}{|c|c|c|}
\hline SESSION & CONTENT & MILESTONES \\
\hline 0 & $\begin{array}{l}\text { Students autodidactically obtain first insights into the programming } \\
\text { language. }\end{array}$ & $\begin{array}{l}\text { Submit a research question that allows the instructor to determine } \\
\text { the groups }\end{array}$ \\
\hline$\underline{1}$ & Introduction to the seminar Organizational issues & Determine project groups based on submitted research questions \\
\hline 2 & Introduction to $\mathrm{R} \mathrm{I:} \mathrm{R} \mathrm{Markdown} \mathrm{and} \mathrm{first} \mathrm{steps} \mathrm{in} \mathrm{R}$ & \\
\hline 3 & $\begin{array}{l}\text { Introduction to R II: Familiarizing students with objects, vectors, and } \\
\text { data frames }\end{array}$ & \\
\hline 4 & Introduction to R III: Importing different data formats & \\
\hline 5 & $\begin{array}{l}\text { Data Wrangling and Merging I: Introducing students to descriptive } \\
\text { statistics }\end{array}$ & Homework 1 (importing datasets) is due \\
\hline 6 & Data Wrangling and Merging II: Wrangling and manipulating data in $\mathrm{R}$ & \\
\hline 7 & Data Wrangling and Merging III: Merging datasets in R & \\
\hline 8 & Data Wrangling and Merging IV: Advanced merging tasks & Homework 2 (data wrangling and manipulation) is due \\
\hline $\begin{array}{l}9 \\
10\end{array}$ & $\begin{array}{l}\text { Data Visualization I: Basics of ggplot2 } \\
\text { Data Visualization II: More advanced ggplot2 }\end{array}$ & \\
\hline $11 \& 12$ & Hackathon & Homework 3 (data visualization) is due \\
\hline 13 & Mini-Conference & Presentation of the group project \\
\hline 14 & Final Session: Outlook and wrap-up & Submission of the term paper \\
\hline
\end{tabular}

\section{Open Access and Reproducibility}

Open access and reproducibility are essential pillars of research. In light of the reproducibility crisis (Baker 2016), training students to perform reproducible research early in their career is essential. To familiarize students with these concepts and teach them a logical workflow that enables them to achieve their goals, I shared all confidently write their own code, learners need sufficient time for practice and exercise, which exceeds executing prewritten lines of code. Therefore, I implemented an inverted classroom setting for this seminar to provide input and assistance during in-class sessions. Students also were asked to practice their skills outside of the classroom. I enabled this by (1) using external learning

\section{Based on my personal experience, to confidently write their own code, learners need sufficient time for practice and exercise, which exceeds executing prewritten lines of code.}

teaching material on GitHub, a cloud-based version control, and RStudio Cloud, a cloud-based version of RStudio Desktop. RStudio Cloud mimics RStudio Desktop on a local machine without installation or operational system-dependent details. ${ }^{5}$ For teaching purposes, this setup is convenient because students can start using the program directly, and they still experience how the program would work on their local machine. Based on my experience, those who needed to transition to the local RStudio Desktop version to work with larger datasets had no difficulty and experienced only a short transition cycle. My teaching material is based on R Markdown files, an efficient and easy-to-use typesetting that is common even outside of academia. Because it provides separate code and text blocks, users can generate reproducible reports in one file (RStudio 2021b). ${ }^{6}$ Although it has an initial steep learning curve, it pays off quickly because it is easily accessible and does not require much in-line coding. Furthermore, it can be compiled as a PDF, HTML, or even Word file and directly communicate research results. For the seminar, I designed an R Markdown template containing a standard structure and a template for the term paper. The templates were reapplied to the students' research projects. ${ }^{7}$

\section{Assignments}

Practical skills such as programming are best learned when they are constantly practiced. Based on my personal experience, to sources, (2) assigning continuous homework submissions, and (3) requiring progress during the group work. Using this combination maintained the constant practice and allowed students to apply their newly gained skills to their own real-world projects.

External learning forums are excellent tools that often offer free and openly accessible teaching material that allows students to practice and revisit their previously learned skills outside of the classroom. ${ }^{8}$ I preselected relevant courses and exercises that I assigned as homework. This allowed students to (re)apply and consolidate their knowledge interactively to new datasets. I also preselected optional advanced courses and listed them in the syllabus to further assist students. This allowed me to accommodate different learning levels. Based on the feedback that I received, course participants were pleased to take advantage of this offer.

\section{Hackathon}

To further support the students' progress, I mimicked the productive atmosphere generated during a hackathon and dedicated a double session to individual course projects at the end of the seminar. This hackathon mirrored a classical hackathon setting, a competitive event that allows participants to dedicate a predefined period to a project with the goal of working collaboratively toward its finalization-well known in tech challenges. Because students 
were required to present their projects and visualizations in a subsequent session, they used the hackathon to polish their work. Hackathons are used widely in learning environments to foster independent learning through applications (Cwikel and Simhi 2021; Kienzler and Fontanesi 2017). The teams consisted of stu-
Students often relied on traditional data using the Uppsala Conflict Data Program's data (UCDP) (Pettersson 2020), the World Bank (2015), and the Armed Conflict Location \& Event Data project (Raleigh et al. 2010), but they also hand-coded their own data. To visualize their findings, students used-for instance-

\section{In addition to demonstrating how it should work, this course equips students with an essential skill: formulating search requests that enable them to find answers to questions themselves.}

dents' previous peer groups with whom they already were working. During the dedicated time, students also had the opportunity to consult with me individually for guidance on finalizing and polishing their visualizations.

\section{Presenting Results as Part of the Mini-Conference}

Good presentation skills are key to delivering a convincing message. This is true for both academic and other contexts. To provide students time to practice these skills, I introduced a mini-conference setting in this course. The session is similar to a traditional academic workshop or a conference, with students serving as presenters and discussants. In this setting, they learned to provide and receive substantial feedback on their work while also improving their presentation skills. For this seminar, students presented the final visualizations with their group. During their presentation, students had to briefly present the relevance of their topic, their individual research questions, and the theoretical reasoning driving their work. Although the focus of the presentation should be the final visualization, the contextual framework was essential to provide substantive feedback. Throughout the presentations, I served as the chair and moderated the feedback rounds. I particularly emphasized their learning to provide and receive feedback from their peers. Using peer feedback as a component in teaching is beneficial because it empowers students to think about and reflect on both their work and others' work (Sackstein 2017). By constantly revising their work in guided steps throughout the course and especially as part of the mini-conference, the students also experienced a typical research and working cycle.

\section{Final Paper}

As part of their final paper, students were asked to present their descriptive visualizations framed in a research note (approximately 2,00o words), including (1) a research question, (2) a short literature review and theoretical assumption, (3) a detailed discussion of their research design, and (4) their interpretation. This approach allows them to practice academic working and writing while keeping the focus of the seminar on the methodological part. To support students with their academic work, I provided individual feedback on their research questions and discussed theoretical mechanisms, data resources, and potential ways to conduct an exploratory analysis. The goal of this course was to allow students to work confidently with $\mathrm{R}$ to generate descriptive statistics. If an instructor prefers more statistics-focused training, this may be integrated into the course setting.

Students' projects were diverse, ranging from analyzing the effects of natural resources or religious diversity on conflict onset to the effects of COVID-19 restrictions on levels of violence. circular plots for relational data, bar plots for share comparisons, and even ShinyApps, interactive web applications in R, to demonstrate the effects of different democracy measures.

\section{CONCLUSION}

Engaging students early with a hands-on course on methods and programming can be a challenging endeavor. Based on my experience, combining a project-based approach with group work allows students to apply their knowledge directly to relevant problems and encourages them to follow a continuous learning process. Acquiring strong and competitive programming and statistics skills is relevant for both academic and nonacademic jobs. Increasingly attractive data-related professions such as data science, data engineering, and data analytics require transferable skills and goal-oriented working behavior. This specific setting demonstrates to students that data usually do not come in the convenient format they often are presented throughout teaching examples, but rather that it often requires much creative thinking to make the data accessible and usable. In addition to demonstrating how it should work, this course equips students with an essential skill: formulating search requests that enable them to find answers to questions themselves. Based on anecdotal evidence, formulating searchable questions has been one of the most challenging components of the course. However, once students have mastered this skill, it allows them to expand their knowledge independently. I also observed this development throughout the course when students used, for instance, YouTube resources to learn how to generate interactive maps in R. The suggested classroom setting equips students with their data science project, which they can use later to demonstrate their skills.

The proposed classroom setting can be applied to various methods courses. Whereas the course described in this article used an introductory methods course, the outline also can be applied to more advanced courses and different statistics and methods subtopics. For example, if a course is designed to replicate one specific scientific process (e.g., producing descriptive findings or running a regression analysis with robustness tests), the single steps can be mimicked. However, for courses in which students are introduced to various methods and analytical approaches, the core part of this course setting-the hands-on and project-based approach-can be applied and transferred. Instead of having one overall example, instructors can use multiple small examples or toy examples to introduce students to the methods. However, in this instance, the general setting of project-based group work and an inverted classroom can remain the same. 


\section{ACKNOWLEDGMENTS}

I thank Sabine Carey (University of Mannheim) for the opportunity to teach seminars at her Chair and also Dennis Hammerschmidt (University of Mannheim), Anna-Lena Hönig (University of Mannheim), Melanie Klinger (University of Mannheim, Department of Educational Development and eLearning), and two anonymous reviewers and the copyeditor for their helpful feedback on earlier versions of an interactive course setup and this article. I also thank the two excellent seminar groups who participated in "Complexities in Analyzing Conflicts: Data Wrangling and Data Management in R" and "Computational Conflict Research: Using R to Analyze Patterns in Conflicts" at the University of Mannheim for being curious enough to try a new setting and to explore the world of R. This work was supported by the University of Mannheim Graduate School of Economic and Social Sciences, funded by the German Research Foundation.

\section{DATA AVAILABILITY STATEMENT}

Additional material related to this article-templates for a syllabus (in LaTeX), a data processing file (R Markdown), and a term paper (R Markdown and LaTeX)-are openly available on the PS: Political Science $\mathcal{E}$ Politics Harvard Dataverse at https://doi.org/10.7910/ DVN/JQLNCT.

\section{NOTES}

1. Due to thematic similarities, students were using similar data sources and could support one another during the data-preparation process while still working individually on their unique research questions.

2. To facilitate the communication within and across the groups, I set up an online communication platform. This was particularly helpful when teaching the methods course in a remote setting.

3. The article by Hultman, Kathman, and Shannon (2014) was an excellent fit for the thematic focus of my methods course (i.e., conflict studies) because it contains publicly accessible datasets and also presents descriptive results visually. Throughout the course, we used data by Kathman (2013) and UCDP (Pettersson 2020) to replicate figures 1-3 from the article. As additional preparation for the seminar students were required to read the text and become familiar with the topic. Because this was due in the first session of the seminar, it also introduced students to the expectations of their final paper.

4. I also developed a student-friendly accessible syllabus in LaTeX that briefly provides all relevant information. (The template can be accessed at https://doi. org/10.7910/DVN/JQLNCT.) In addition to other information, the syllabus contains for each seminar session a short description of the topic, additional input provided by online learning courses, and exercises with preselected courses that allow students to practice skills covered during class sessions. The syllabus also goes beyond what we learned in class for those eager to learn more, and it includes excellent and open-source CheatSheets that cover exactly what we learned during class sessions. The syllabus also contains detailed and transparent information on the assessment criteria for the coursework examination. This way, students already have a clear understanding of what is expected of them at the beginning of the course.

5. Although there are different plans for an RStudio Cloud solution, I relied on the free plan, which was sufficient for teaching purposes.

6. Because Markdown also uses features of LaTeX, I offered an optional workshop; however, this is not essential for students to sufficiently understand Markdown.

7. The template is accessible at https://doi.org/10.7910/DVN/JQLNCT. I also provided a template that allows students to generate their term papers directly from their $\mathrm{R}$ Markdown syntax. The template is available online at https://doi org/10.7910/DVN/JQLNCT.

8. The R packages learnr (RStudio 2021a) and swearl (Kross et al. 2020) allow instructors to set up individual tasks themselves. Tinystats (Walum and De Leon 2021) is a setup of an interactive walk-through on basic statistics that allows participants to read texts and learn from visualization and their own practice. The company RStudio (2021c) offers many open-access webinars that students can revisit, and there is a lively $\mathrm{R}$ community that offers regular meetings and trainings (often free or low cost) around the world. For example, the R-Ladies (2021) provide an inclusive network that spans the globe and SatRdays (2021) offers conferences and free (or low-cost) trainings.

\section{REFERENCES}

Adeney, Katharine, and Sean Carey. 2009. "Contextualising the Teaching of Statistics in Political Science.” Politics 29 (3): 193-200. https://doi.org/10.1111/j.14679256.2009.01355.x.

Asal, Victor, Nakissa Jahanbani, Donnett Lee, and Jiacheng Ren. 2018. "Mini-Games for Teaching Political Science Methodology.” PS: Political Science \& Politics 51 (4): 838-41. https://doi.org/10.1017/S1049096518000902.

Bailey, Michael A. 2019. "Teaching Statistics: Going from Scary, Boring, and Useless to, Well, Something Better." PS: Political Science \& Politics 52 (2): 367-70. https:// doi.org/10.1017/S1049096518002044.

Baker, Monya. 2016. "Reproducibility Crisis." Nature 533 (26): 353-66.

Chen, Tzer-Long, Tsung-Chih Hsiao, Tsan-Ching Kang, Ting-Yuan Wu, and ChihCheng Chen. 2020. "Learning Programming Language in Higher Education for Sustainable Development: Point-Earning Bidding Method." Sustainability 12 (11) 4489. https://doi.org/10.3390/su12114489.

Cwikel, Julie, and Meital Simhi. 2021. "Using the Hackathon Model in Social Work Education." Social Work Education April:1-14. https://doi.org/10.1080/ 02615479.2021.1910654

daSilva, Alex. 2019. "R vs Python: Comparing Data Science Job Postings Seeking R or Python Specialists." https://towardsdatascience.com/r-vs-python-comparingdata-science-job-postings-seeking-r-or-python-specialists-2c39baz6d 471.

Forte, James A. 1995. "Teaching Statistics without Sadistics." Journal of Social Work Education 31 (2): 204-18. https://doi.org/10.1080/10437797.1995.10672258.

Hultman, Lisa, Jacob D. Kathman, and Megan Shannon. 2014. "Beyond Keeping Peace: United Nations Effectiveness in the Midst of Fighting." American Politica Science Review 108 (4): 737-53. https://doi.org/10.1017/Sooo3055414000446.

Kathman, Jacob D. 2013. "United Nations Peacekeeping Personnel Commitments, 1990-2011." Conflict Management and Peace Science 30 (5): 532-49. https:// doi.org/10.1177/0738894213491180.

Kienzler, Hanna, and Carolyn Fontanesi. 2017. "Learning through Inquiry: A Global Health Hackathon." Teaching in Higher Education 22 (2): 129-42. https:// doi.org/10.1080/13562517.2016.1221805.

Knoll, Benjamin R. 2016. "Learning by Doing: Mentoring Group-Based Undergraduate Research Projects in an Upper-Level Political Science Course." PS Political Science \& Politics 49 (1): 128-31. https://doi.org/10.1017/ S1049096515001146.

Krajcik, Joseph S., and Phyllis C. Blumenfeld. 2006. "Project-Based Learning." In The Cambridge Handbook of the Learning Sciences, ed. R. Keith Sawyer, 317-34 New York: Cambridge University Press.

Kross, Sean, Nick Carchedi, Bill Bauer, and Gina Grdina. 2020. Swirl: Learn $R$, in $R$ (Version R Package Version 2.4.5). https://CRAN.R-project.org/package=swirl.

Låg, Torstein, and Rannveig Grøm Sæle. 2019. "Does the Flipped Classroom Improve Student Learning and Satisfaction? A Systematic Review and Meta-Analysis." AERA Open 5 (3): 1-17. https://doi.org/10.1177/2332858419870489.

Ozgur, Ceyhun, Taylor Colliau, Grace Rogers, Zachariah Hughes, and Elyse "Bennie" Myer-Tyson. 2017. "MatLab vs. Python vs. R.” Journal of Data Science 15:355-72. https://doi.org/10.6339/JDS.201707_15(3).0001.

Pettersson, Therese. 2020. "UCDP/PRIO Armed Conflict Dataset Codebook v 20.1." https://ucdp.uu.se/downloads.

Raleigh, Clionadh, Andrew Linke, Håvard Hegre, and Joakim Karlsen. 2010. "Introducing ACLED: An Armed Conflict Location and Event Dataset: Special Data Feature." Journal of Peace Research 47 (5): 651-6o. https://doi.org/10.1177/ 0022343310378914.

R-Ladies. 2021. “R-Ladies Global.” https://rladies.org.

RStudio. 2021a. Interactive Tutorials for R. https://rstudio.github.io/learnr.

RStudio. 2021b. "R Markdown.” https://rmarkdown.rstudio.com.

RStudio. 2021c. "RStudio Webinars." https://rstudio.com/resources/webinars.

Sackstein, Starr. 2017. Peer Feedback in the Classroom: Empowering Students to Be the Experts. www.myilibrary.com?id=1004967.

SatRdays. 2021. "SatRdays." https://satrdays.org.

Shaw, Ruey-Shiang. 2012. "A Study of the Relationships among Learning Styles, Participation Types, and Performance in Programming Language Learning Supported by Online Forums." Computers \& Education 58 (1): 111-20. https:// doi.org/10.1016/j.compedu.2011.08.013.

Walum, Hasse, and Desirée De Leon. 2021. “Tinystats.” https://tinystats.github.io/ teacups-giraffes-and-statistics/index.html.

Williams, Unislawa, Robert Brown, Marilyn Davis, Tinaz Pavri, and Fatemeh Shafiei. 2021. "Teaching Data Science in Political Science: Integrating Methods with Substantive Curriculum." PS: Political Science \& Politics 54 (2): 336-39. https:// doi.org/10.1017/S1049096520001687.

World Bank Data. 2015. "Worldwide Governance Indicators." http:// info.worldbank.org/governance/wgi/index.aspx\#home. 